\title{
Исследование температурной зависимости границ спектральной характеристики чувствительности фотомодулей на основе КРТ
}

\author{
В.С. Ковшов ${ }^{1,2}$, А.В. Никонов ${ }^{2}$, К.О. Болтарь ${ }^{1,2}$ \\ ${ }^{1}$ АО «НПО «Орион», Москва, 111538, ул. Косинская, 9 \\ ${ }^{2}$ МФТИ (НИУ), Долгопрудный, 141701, Институтский пер., 9 \\ тел:+7 (916) 333-4011, эл. почта: ech@li.ru
}

DOI 10.34077/RCSP2021-141

Повышение требований к тактико-техническим характеристикам оптико-электронных систем ИКдиапазона, наблюдаемое в последнее десятилетие, является катализатором для непрерывного совершенствования и оптимизации технологии изготовления современных фотоприемных устройств. Особые требования предъявляются в первую очередь к полупроводниковым материалам и соединениям на их основе, используемым для изготовления фоточувствительных элементов. Фотомодули на основе гетероэпитаксиальных структур тройных соединений кадмий-ртуть-теллур (КРТ) стабильно занимают широкую область рынка изделий фотоэлектроники $[1,2]$. Вместе с тем, перед разработчиками стоит вопрос совершенствования технологии изготовления таких фотомодулей.

В данной работе представлены результаты моделирования зависимости длинноволновой границы спектрального диапазона чувствительности фотомодулей на основе КРТ от рабочей температуры фотоприемного устройства для различных способов изготовления гетероэпитаксиальных структур КРТ. В расчётной модели за основу взята широко известная формула зависимости ширины запрещенной зоны от состава $x$ соединения $C d_{x} H g_{1-x} T e$ и температуры [3]:

$$
E_{g}=-0,303 \cdot(1-x)+1,606 x-0,132 x(1-x)+\frac{6,3 \cdot(1-x)-3,25 x-5,92 x(1-x)}{11 \cdot(1-x)+78,7 x+T} \cdot 10^{-4} T^{2} .
$$

При использовании данной зависимости, а также принимая во внимание связь энергии с длиной волны излучения, становится возможным рассчитать длинноволновой границы чувствительности фотомодулей. Как правило, зависимость такого рода применяется для проведения предварительной ориентировочной оценки диапазона чувствительности при известном составе КРТ и нормальных климатических условиях.

В расчетной модели использованы экспериментальные результаты измерения спектральной характеристики чувствительности фотомодулей на основе гетероэпитаксиальных структур КРТ, выращенных различными способами. Статистическая обработка экспериментальных данных проводилась по выборке измеренных при 77 К спектральных характеристик чувствительности 37 фотомодулей на основе структур КРТ различного состава, выращенных методом молекулярно-лучевой эпитаксии, и 42 фотомодулей на основе структур, выращенных методом жидкофазной эпитаксии. Также использованы экспериментальные данные контроля сдвига длинноволновой границы чувствительности при измерениях спектральных характеристик чувствительности выборочных фотоприемных модулей с различным составом КРТ на диапазоне температур от 77 К до 150 К.

При использовании метода пакетного градиентного спуска в сравнении расчётных значений длинноволновой границы чувствительности с экспериментальными данными нами получены уточненные эмпирические формулы зависимости длинноволновой границы чувствительности фотомодулей на основе КРТ, выращенных методами молекулярно-лучевой и жидкофазной эпитаксии. Применение полученных в ходе работы результатов позволяет в экспресс-режиме прогнозировать значения длинноволновой границы чувствительности с повышенной точностью по паспортным данным состава материала в пластинах КРТ, в том числе принимать во внимание возможное наличие градиента состава по поверхности пластины.

\section{Лuтература}

[1] Н.И. Яковлева, К.О. Болтарь и др. // Прикладная физика. 2018. № 6. С. 29-34.

[2] N.I. Iakovleva, K.O. Boltar et al. // J. Commun. Technol. Electron. 2018. № 9. P. 1132-1136.

[3] J.P.Laurenti, J. Camassel et al. // J. Appl. Phys. 1990. N 67. P. 6454. 